\title{
The Prospective Health Assessment of Cataract Patients' Ocular Surface (PHACO) study: the effect of dry eye
}

This article was published in the following Dove Press journal:

Clinical Ophthalmology

7 August 2017

Number of times this article has been viewed

\author{
William B Trattler' \\ Parag A Majmudar ${ }^{2}$ \\ Eric D Donnenfeld ${ }^{3}$ \\ Marguerite B McDonald ${ }^{4}$ \\ Karl G Stonecipher ${ }^{5}$ \\ Damien F Goldberg ${ }^{6}$ \\ On behalf of the PHACO \\ Study Group \\ 'Center for Excellence in Eye \\ Care, Miami, FL, USA; ${ }^{2}$ Chicago \\ Cornea Consultants, Chicago, IL, \\ USA; ${ }^{3}$ Ophthalmic Consultants of \\ Long Island, Garden City, NY, USA; \\ ${ }^{4}$ Ophthalmic Consultants of Long \\ Island, Lynbrook, NY, USA; ${ }^{5}$ University \\ North Carolina School of Medicine, \\ Chapel Hill, NC, USA; 'Wolstan \& \\ Goldberg Eye Associates, Torrance, \\ CA, USA
}

Purpose: To determine the incidence and severity of dry eye as determined by the International Task Force (ITF) scale in patients being screened for cataract surgery.

Patients and methods: This was a prospective, multi-center, observational study of 136 patients, at least 55 years of age, who were scheduled to undergo cataract surgery. The primary outcome measure was the incidence of dry eye as evaluated by grade on the ITF scale and secondary outcome measures include tear break-up time (TBUT), ocular surface disease index score, corneal staining with fluorescein, conjunctival staining with lissamine green, and a patient questionnaire to evaluate symptoms of dry eye.

Results: Mean patient age was 70.7 years. A total of $73.5 \%$ of patients were Caucasian and $50 \%$ were female. Almost $60 \%$ had never complained of a foreign body sensation; only $13 \%$ complained of a foreign body sensation half or most of the time. The majority of patients $(62.9 \%)$ had a TBUT $\leq 5$ seconds, $77 \%$ of eyes had positive corneal staining and $50 \%$ of the eyes had positive central corneal staining. Eighteen percent had Schirmer's score with anesthesia $\leq 5 \mathrm{~mm}$.

Conclusion: The incidence of dry eye in patients scheduled to undergo cataract surgery in a real-world setting is higher than anticipated.

Keywords: cataract surgery screening, dry eye, International Task Force scale, observational study

\section{Introduction}

Despite the generally positive outcomes of cataract surgery, some patients are dissatisfied with their postoperative result due to a suboptimal refractive outcome that may be the result of unresolved issues on the ocular surface..$^{1-3}$ Ongoing and increasing awareness of these issues has led to anterior segment surgeons commonly performing an array of preoperative evaluations and prescribing treatments to optimize the ocular surface and ensure the health of the cornea and retina before patients undergo cataract surgery. ${ }^{4}$ Even with the ocular surface evaluation performed preoperatively, the incidence of dry eye after phacoemulsification has been reported to be $9.8 \% .^{5}$ Additionally, Cho and Kim found the type of wound created during cataract surgery could exacerbate patient-reported symptoms in those previously thought to be disease-free. ${ }^{1}$

The diagnosis of dry eye can be challenging, as some studies have found that nearly $50 \%$ of dry eye patients may show no corneal staining, despite other evidence of dry eye disease (increased tear osmolarity, reduced Schirmer's scores, or presence of dry eye symptoms). ${ }^{6}$ Earlier studies showed that dry eye symptoms, such as blurred vision, are sometimes erroneously attributed to the cataract, which may contribute to the higher postoperative incidence. ${ }^{7}$
Correspondence: William B Trattler Center for Excellence in Eye Care, 8940 North Kendall Drive, \#400E Miami, FL 33176, USA

Email wtrattler@gmail.com 
Cataract surgery has been reported in the literature to induce dry eye and to exacerbate pre-existing dry eye. . $^{1,2,5,8-14}$ Treatments for postoperative dry eye have been extensively reported in the literature and include nonsteroidal antiinflammatory drugs, topical corticosteroids, artificial tears, topical cyclosporine $0.05 \%$, lifitegrast, $3.0 \%$ diquafosol, $1 \%$ carboxymethylcellulose sodium, oral lactoferrin, oral doxycycline, punctal plugs, and autologous serum, among others. ${ }^{3,8,10,15-24}$ Yet, little has been reported in the literature on the preoperative incidence of dry eye in a cataract population.

We hypothesized that the incidence of pre-existing dry eye disease in patients who are scheduled to undergo cataract surgery is higher than previously thought based on the published literature. The Prospective Health Assessment of Cataract Patients' Ocular Surface (PHACO) study sought to determine the incidence of dry eye and its severity (as determined by the International Task Force [ITF] scale) ${ }^{25}$ in patients undergoing cataract surgery and to assess the signs and symptoms of dry eye in this patient population.

\section{Patients and methods}

This was a prospective, multicenter, observational study of 143 consecutive patients at least 55 years of age scheduled to undergo standard phacoemulsification cataract surgery in one or two eyes at one of nine clinical sites in the US and Canada. Exclusion criteria included any previous intraocular surgery in the previous 3 months before enrollment; subjects without visually significant cataract, corneal laser vision correction surgery in either eye in the previous year; previous lid surgery within 3 months; and use of topical antibiotics, topical nonsteroidal anti-inflammatory drugs, or topical steroid in either eye. Those subjects who had recently initiated topical cyclosporine $0.05 \%$ use for dry eye were excluded from study testing, but were asked to complete a questionnaire about medication use and any additional dry eye treatments (ie, warm compresses). Although lifitegrast is currently approved for the treatment of both signs and symptoms of dry eye, that pharmacologic treatment was not approved in the US at the time of this study.

Preoperatively, all eligible subjects underwent ocular surface testing in both eyes that included tear break-up time (TBUT), corneal and conjunctival staining (with fluorescein and lissamine green, respectively) according to the National Eye Institute (NEI) grid, ${ }^{26}$ Schirmer's score evaluation with anesthesia, ${ }^{27}$ Ocular Surface Disease Index (index range from $0-100$ ), ${ }^{28,29}$ and a patient questionnaire to assess dry eye symptoms (if any). For the purposes of this study, a TBUT $>10$ seconds was considered abnormal, with TBUT $>5$ seconds considered highly likely of dry eye symptoms.

In this study, corneal staining was evaluated under cobalt blue illumination 2.5-3 minutes after fluorescein instillation and conjunctival staining was performed 2.5-3 minutes after $10 \mu \mathrm{L}$ of a $1 \%$ sodium lissamine green dye was instilled. Both of these followed the NEI scale. ${ }^{26}$

Written consent to publish their data was obtained from all patients prior to being enrolled in the study. This research was approved by the Institutional Review Board Company, Inc. (Buena Park, CA, USA). As this was an observational study, it was not powered to determine statistical significance. Similarly, there was no control arm as all subjects were predetermined to have visually significant cataract. All analyses were descriptive in nature and used StatView Software (SAS Institute, Cary, NC, USA).

\section{Results}

\section{Patient demographics}

There were 143 patients (286 eyes) scheduled to undergo routine cataract surgery who met the initial inclusion criteria. The mean age of the patients was $70.7 \pm 7.8$ years (range: $54.5-87.9$ years). Seven patients (4.9\%) were using topical cyclosporine $0.05 \%$ at the time of presentation and were excluded from this analysis. Among the remaining 136 patients ( 272 eyes) included in this analysis, there were 100 Caucasian patients (73.5\%), 15 Hispanic patients (11.0\%), 11 Asian patients (8.1\%), five black patients (3.7\%), and five who identified their race as "other" (3.7\%).

Thirty patients (22.1\%) had received a prior diagnosis of dry eye but were not on prescription or over-the-counter treatments; 68 patients $(50 \%)$ were male. If the previously excluded seven patients who were using topical cyclosporine $0.05 \%$ had been included in this analysis, the percentage of patients with a previous diagnosis of dry eye would increase to $25.9 \%$.

The incidence of dry eye as evaluated by the $\operatorname{ITF}^{25}$ level included 34 patients (25\%) at level 0 and 39 patients (28.7\%) at level 3 (Table 1).

Using the NEI scale to assess corneal staining, ${ }^{7} 61$ patients (44.9\%) had a corneal staining score of $\geq 1$. These same

Table I Incidence of dry eye as evaluated by ITF

\begin{tabular}{lll}
\hline ITF level & $\begin{array}{l}\text { Number } \\
\text { of patients }\end{array}$ & $\begin{array}{l}\text { Percentage } \\
\text { of cohort }\end{array}$ \\
\hline 0 & 34 & 25 \\
1 & 27 & 19.9 \\
2 & 36 & 26.5 \\
3 & 39 & 28.7 \\
4 & 0 & 0 \\
\hline
\end{tabular}

Abbreviation: ITF, International Task Force. 
patients had a cumulative score of $\leq 1$ (on a scale of 1-4) in burning/stinging, foreign body sensation, dryness, and pain/soreness.

Similarly, the mean ( \pm standard deviation) TBUT score was $4.95 \pm 2.5$ seconds (range $0-15$ seconds); 171 eyes (62.9\%) had TBUT scores of $\leq 5$ seconds; 58 eyes (21.3\%) had Schirmer's scores of $\leq 5 \mathrm{~mm}$ (mean $12.4 \pm 7.3 \mathrm{~mm}$; range $0-35 \mathrm{~mm}$ ); and 209 eyes $(76.8 \%)$ had positive fluorescein corneal staining scores (mean 4.3 \pm 3.5 ; range $0-15$ ), with 136 eyes (50\%) also showing positive central staining. The mean lissamine staining score was $0.92 \pm 0.61$, with a range of 0-2.8 (Table 2).

\section{Subjective analyses}

All patients $(\mathrm{N}=136)$ completed a dry eye signs and symptoms questionnaire (Table S1). Patients were allowed to provide more than one response to each question. The majority (94/136; 69.1\%) reported no stinging and burning. Eighty-six patients $(63.2 \%)$ were never affected by the symptom of dryness; 80 patients $(58.8 \%)$ reported no foreign body sensation; 73 patients (53.7\%) reported no itching; 53 patients (39\%) reported no sensitivity to light; 107 patients $(78.7 \%)$ reported no pain/soreness; 46 patients (33.8\%) reported no blurred vision; 50 patients (36.8\%) reported blurred vision "some of the time"; and 65 patients $(47.8 \%)$ reported their eyes never felt tired or fatigued.

When patients were asked about their employment and productivity on a daily basis, most reported missing

Table 2 TBUT, Schirmer's score, and staining scores*

\begin{tabular}{|c|c|c|}
\hline Testing method & $\begin{array}{l}\text { Number of eyes } \\
\mathbf{N}=\mathbf{2 7 2}\end{array}$ & $\begin{array}{l}\text { Percentage } \\
\text { of eyes }\end{array}$ \\
\hline \multicolumn{3}{|l|}{ TBUT $(n=268)$} \\
\hline$\leq 5$ seconds & 171 & 62.9 \\
\hline$>5$ seconds & 97 & 35.6 \\
\hline Missing & 4 & 1.5 \\
\hline \multicolumn{3}{|c|}{ Schirmer's scores (n=272) } \\
\hline$\leq 5 \mathrm{~mm}$ & 58 & 21.3 \\
\hline$\leq 10 \mathrm{~mm}$ & 214 & 78.7 \\
\hline \multicolumn{3}{|c|}{ Corneal staining (fluorescein) $(n=27 I)$} \\
\hline Positive & 209 & 76.8 \\
\hline Negative & 62 & 22.8 \\
\hline Missing & I & 0.4 \\
\hline \multicolumn{3}{|c|}{ Central staining (fluorescein) $(n=27 I)$} \\
\hline Positive & 136 & 50 \\
\hline Negative & 135 & 49.6 \\
\hline Missing & I & 0.4 \\
\hline \multicolumn{3}{|c|}{ Conjunctival staining (lissamine) $(n=27 I)$} \\
\hline Mean & 0.92 & \\
\hline Standard deviation & 0.61 & \\
\hline Minimum & 0 & \\
\hline Maximum & 2.8 & \\
\hline
\end{tabular}

Note: *Not all patients completed all preoperative corneal testing.

Abbreviation: TBUT, tear break-up time.
0-2 hours of work weekly due to health problems and the majority reported their health problems did not affect work productivity or daily activities.

\section{Discussion}

In our observational study, fewer than $25 \%$ of patients had been previously diagnosed with dry eye when they presented for cataract surgery, yet 30\% reported at least occasional symptoms (Table S1). Our results add to the literature findings of diagnosed dry eye prevalence rates between 3.5\% and $33.7 \% .^{30}$

Dry eye is already considered both underdiagnosed and undertreated, and our findings support that belief. ${ }^{16,31-43}$ It is now well accepted that people affected by dry eye are often more symptomatic than clinical tests may indicate, ${ }^{44,45}$ and in our study, almost $45 \%$ had a corneal staining score of at least 1 , but a cumulative score of $\leq 1$ in traditionally reported subjective symptoms of dry eye including burning/ stinging, foreign body sensation, dryness, and pain/soreness. This suggests that somewhere between $15 \%$ and $20 \%$ of our study population would have eluded the diagnosis of dry eye suspect/confirmed dry eye had they not presented for cataract surgery evaluation. The visual complications associated with dry eye are well reported, as is the risk of postoperative complications after cataract surgery in known dry eye patients. ${ }^{9,46-55}$

With more than 24 million Americans affected by cataracts, ${ }^{56}$ there is an increased need to ensure preoperative evaluations encompass all aspects that may have a deleterious effect on postoperative outcomes. This should include an evaluation of the ocular surface, as suggested by the American Academy of Ophthalmology. ${ }^{56}$

Ten seconds has been the usual cutoff for an abnormal TBUT; some studies indicate 7 seconds will identify more patients with poor ocular surfaces, ${ }^{57}$ and a cutoff of 5 seconds is generally accepted as definitive dry eye. ${ }^{52}$

In our study, the mean TBUT was 4.95 seconds and $>80 \%$ of our patients had a TBUT of $\leq 7$ seconds. Additionally, $76.8 \%$ of patients in our study were positive for fluorescein staining, while $50 \%$ showed positive central staining as well. A large number of eyes ( $\mathrm{n}=95,46.6 \%)$ had Schirmer's scores of $\leq 10$. Our results suggest that more than one diagnostic test may be necessary to identify those with undiagnosed preoperative dry eye.

This study is not without its limitations. We included only those patients who were already identified with a visually significant cataract and did not include those in whom a cataract had not yet reached a visually significant level. The investigators were not masked to the findings, as all our patients 
undergo these evaluations before being cleared for cataract surgery. We also did not include age-matched control subjects, as this study was designed to be observational and not interventional. These decisions may have skewed our results in that our patient population was older and more likely to have dry eye. However, we attempted to compensate for that by eliminating patients who were already diagnosed with dry eye and were on a prescription treatment from our analysis. It is interesting to note, however, that only seven patients were actively being treated, although substantially more $(n=30)$ had been previously diagnosed, adding to our supposition that if dry eye is not being actively screened for in this patient population, it may be overlooked altogether. Although the study had strict exclusion criteria to eliminate other disorders and known treatments that are associated with dry eye or its treatment (such as topical steroid use), we did not exclude patients who used antihistamines, antidepressants, or anticholinergic drugs because the literature has shown that while the latter may have an association with dry eye, different drugs within those classes may alleviate, exacerbate, or have no effect on dry eye. ${ }^{58-63}$ It was not the purpose of this study to determine the cause of dry eye, just to ascertain its presence.

The evaluations were conducted at a time when newer diagnostic modalities such as tear osmolarity and methods to detect the presence of inflammatory markers were not available. It is possible that the true incidence of dry eye might have been even higher had those modalities been included in the overall assessment. Finally, as an observational study, it is subject to all the potential biases inherent with these types of evaluations.

However, this study also has numerous strengths. Enrolled patients had already undergone extensive preoperative assessment, both of their cataract and of their overall ocular health, consistent with commonly used cataract assessment parameters. As such, patients with known dry eye or presumed dry eye that may be the result of glaucoma medication use, or disorders such as meibomian gland dysfunction, chronic conjunctivitis, or trichiasis, would have been excluded from our analysis. To our knowledge, this is the first study to evaluate preoperative levels of dry eye in a real-world cataract population, regardless of a previous diagnosis or lack thereof. We encourage further exploration on our findings, especially as they may relate to potential cataract surgery outcomes.

\section{Conclusion}

The percentage of prospective cataract patients who have signs or symptoms of dry eye continues to be underreported; increased awareness should lead to careful monitoring of the patient's ocular health both before and after surgery.

\section{Acknowledgments}

This study was funded by an unrestricted grant from Allergan. Members of the PHACO study group are consultants to Allergan. EDD, MBM, KGS, DFG, and WBT are also consultants to Shire. Michelle Dalton, ELS, provided medical writing and editing; this support was funded by an unrestricted grant from Allergan, Irvine, CA, USA.

This paper was presented in part at the American Society of Cataract \& Refractive Surgery annual meetings in 2011 (San Diego, CA; March 25-29) and 2012 (Chicago, IL, April 20-24).

Members of the PHACO Study Group: Damien F Goldberg, MD; Chaz Reilly, MD; Mark Packer, MD; Parag A Majmudar, MD; Eric D Donnenfeld, MD; Marguerite B McDonald, MD, FACS; Karl G Stonecipher, MD; Jon Vukich, MD; Gregg Berdy, MD; Ranjan Malahotra, MD; and William B Trattler, MD.

\section{Author contributions}

WBT, PAM, EDD, MBM, KGS, and DFG conducted the study; WBT, PAM, EDD, MBM, KGS, and DFG analyzed data and revised the paper; and WBT, PAM, EDD, MBM, $\mathrm{KGS}$, and DFG reviewed and approved the manuscript.

\section{Disclosure}

None of the authors have a financial interest in any product mentioned, but all are consultants to Allergan. In addition, EDD, MBM, KGS, and WBT are consultants to Shire. The authors report no other conflicts of interest in this paper.

\section{References}

1. Cho YK, Kim MS. Dry eye after cataract surgery and associated intraoperative risk factors. Korean J Ophthalmol. 2009;23(2):65-73.

2. Han KE, Yoon SC, Ahn JM, et al. Evaluation of dry eye and meibomian gland dysfunction after cataract surgery. Am J Ophthalmol. 2014;157(6):1144.e1-1150.e1.

3. Yao K, Bao Y, Ye J, et al. Efficacy of $1 \%$ carboxymethylcellulose sodium for treating dry eye after phacoemulsification: results from a multicenter, openlabel, randomized, controlled study. BMC Ophthalmol. 2015;15:28.

4. Movahedan A, Djalilian AR. Cataract surgery in the face of ocular surface disease. Curr Opin Ophthalmol. 2012;23(1):68-72.

5. Kasetsuwan N, Satitpitakul V, Changul T, Jariyakosol S. Incidence and pattern of dry eye after cataract surgery. PLoS One. 2013;8(11): e78657.

6. Sullivan BD, Crews LA, Sönmez B, et al. Clinical utility of objective tests for dry eye disease: variability over time and implications for clinical trials and disease management. Cornea. 2012;31(9):1000-1008.

7. Lemp MA. Report of the National Eye Institute/Industry workshop on clinical trials in dry eyes. CLAO J. 1995;21(4):221-232.

8. Lee JH, Song IS, Kim KL, Yoon SY. Effectiveness and optical quality of topical $3.0 \%$ diquafosol versus $0.05 \%$ cyclosporine $\mathrm{A}$ in dry eye patients following cataract surgery. J Ophthalmol. 2016;2016:8150757. 
9. Kwon JW, Chung YW, Choi JA, La TY, Jee DH, Cho YK. Comparison of postoperative corneal changes between dry eye and non-dry eye in a murine cataract surgery model. Int J Ophthalmol. 2016; 9(2):218-224.

10. Yu Y, Hua H, Wu M, et al. Evaluation of dry eye after femtosecond laser-assisted cataract surgery. J Cataract Refract Surg. 2015; 41(12):2614-2623.

11. Balaram M, Dana MR. Phacoemulsification in patients after allogeneic bone marrow transplantation. Ophthalmology. 2001;108(9): $1682-1687$.

12. Liu X, Gu YS, Xu YS. Changes of tear film and tear secretion after phacoemulsification in diabetic patients. $J$ Zhejiang Univ Sci B. 2008;9(4):324-328.

13. Oh T, Jung Y, Chang D, Kim J, Kim H. Changes in the tear film and ocular surface after cataract surgery. Jpn J Ophthalmol. 2012;56(2):113-118.

14. Li XM, Zhao X, Hu LZ, Wang W. [Clinical observation of dry eye in patients before and after cataract surgery]. Zhonghua Yan Ke Za Zhi. 2007;43(1):10-13. German.

15. Management and therapy of dry eye disease: report of the Management and Therapy Subcommittee of the International Dry Eye WorkShop (2007). Ocul Surf. 2007;5(2):163-178.

16. Gayton JL. Etiology, prevalence, and treatment of dry eye disease. Clin Ophthalmol. 2009;3:405-412.

17. Sánchez MA, Arriola-Villalobos P, Torralbo-Jiménez P, et al. The effect of preservative-free HP-Guar on dry eye after phacoemulsification: a flow cytometric study. Eye (Lond). 2010;24(8):1331-1337.

18. Sandoval HP, Fernández de Castro LE, Vroman DT, Solomon KD A review of the use of ketorolac tromethamine $0.4 \%$ in the treatment of post-surgical infl ammation following cataract and refractive surgery. Clin Ophthalmol. 2007;1(4):367-371.

19. Devendra J, Singh S. Effect of Oral Lactoferrin on Cataract Surgery Induced Dry Eye: A Randomised Controlled Trial. J Clin Diagn Res. 2015;9(10):NC06-NC09.

20. Pan Q, Angelina A, Zambrano A, et al. Autologous serum eye drops for dry eye. Cochrane Database Syst Rev. 2013(8):CD009327.

21. Chung YW, Oh TH, Chung SK. The effect of topical cyclosporine $0.05 \%$ on dry eye after cataract surgery. Korean $J$ Ophthalmol. 2013;27(3):167-171.

22. Galor A, Zheng DD, Arheart KL, et al. Dry eye medication use and expenditures: data from the medical expenditure panel survey 2001 to 2006. Cornea. 2012;31(12):1403-1407.

23. Perez VL, Pflugfelder SC, Zhang S, et al. Lifitegrast, a novel integrin antagonist for treatment of dry eye disease. Ocul Surf. 2016 14(2):207-215.

24. Sheppard JD, Torkildsen GL, Lonsdale JD, et al. Lifitegrast ophthalmic solution $5.0 \%$ for treatment of dry eye disease: results of the OPUS-1 phase 3 study. Ophthalmology. 2014;121(2):475-483.

25. Behrens A, Doyle JJ, Stern L, et al. Dysfunctional tear syndrome: a Delphi approach to treatment recommendations. Cornea. 2006;25(8):900-907.

26. Lemp MA. Report of the National Eye Institute/Industry workshop on clinical trials in dry eyes. CLAO J. 1995;21(4):221-232.

27. Savini G, Prabhawasat P, Kojima T, Grueterich M, Espana E, Goto E. The challenge of dry eye diagnosis. Clin Ophthalmol. 2008;2(1):31-55.

28. Dougherty BE, Nichols JJ, Nichols KK. Rasch analysis of the Ocular Surface Disease Index (OSDI). Invest Ophthalmol Vis Sci. 2011;52(12):8630-8635.

29. Schiffman RM, Christianson MD, Jacobsen G, Hirsch JD, Reis BL Reliability and validity of the Ocular Surface Disease Index. Arch Ophthalmol. 2000;118(5):615-621.

30. [No authors listed]. The epidemiology of dry eye disease: report of the Epidemiology Subcommittee of the International Dry Eye WorkShop (2007). Ocul Surf. 2007;5(2):93-107.

31. Asbell PA, Spiegel S. Ophthalmologist perceptions regarding treatment of moderate-to-severe dry eye: results of a physician survey. Eye Contact Lens. 2010;36(1):33-38.
32. [No authors listed]. The definition and classification of dry eye disease: report of the Definition and Classification Subcommittee of the International Dry Eye WorkShop (2007). Ocul Surf. 2007;5(2):75-92.

33. Imbert Y, Foulks GN, Brennan MD, et al. MUC1 and estrogen receptor alpha gene polymorphisms in dry eye patients. Exp Eye Res. 2009; 88(3):334-338.

34. Jackson WB. Management of dysfunctional tear syndrome: a Canadian consensus. Can J Ophthalmol. 2009;44(4):385-394.

35. Khaireddin R, Schmidt KG. [Comparative investigation of treatments for evaporative dry eye]. Klin Monbl Augenheilkd. 2010; 227(2):128-134. Chinese.

36. Pflugfelder SC. Antiinflammatory therapy for dry eye. Am J Ophthalmol. 2004;137(2):337-342.

37. Pflugfelder SC. Dry eye. Focal Points. 2006;25(5):1-15.

38. Pflugfelder SC, de Paiva CS, Tong L, Luo L, Stern ME, Li D. Stressactivated protein kinase signaling pathways in dry eye and ocular surface disease. Ocul Surf. 2005;3(4 Suppl):S154-S157.

39. Sullivan DA, Sullivan BD, Evans JE, et al. Androgen deficiency, Meibomian gland dysfunction, and evaporative dry eye. Ann N Y Acad Sci. 2002;966:211-222.

40. Lee SY, Petznick A, Tong L. Associations of systemic diseases, smoking and contact lens wear with severity of dry eye. Ophthalmic Physiol Opt. 2012;32(6):518-526.

41. Schaumberg DA, Dana R, Buring JE, Sullivan DA. Prevalence of dry eye disease among US men: estimates from the Physicians' Health Studies. Arch Ophthalmol. 2009;127(6):763-768.

42. Schaumberg DA, Sullivan DA, Buring JE, Dana MR. Prevalence of dry eye syndrome among US women. Am J Ophthalmol. 2003; 136(2):318-326.

43. Yazdani C, McLaughlin T, Smeeding JE, Walt J. Prevalence of treated dry eye disease in a managed care population. Clin Ther. 2001; 23(10):1672-1682.

44. Chalmers RL, Begley CG, Edrington T, et al. The agreement between self-assessment and clinician assessment of dry eye severity. Cornea. 2005;24(7):804-810.

45. Sullivan BD, Crews LA, Messmer EM, et al. Correlations between commonly used objective signs and symptoms for the diagnosis of dry eye disease: clinical implications. Acta Ophthalmol. 2014;92(2):161-166.

46. Chotikavanich S, de Paiva CS, Li de Q, et al. Production and activity of matrix metalloproteinase-9 on the ocular surface increase in dysfunctional tear syndrome. Invest Ophthalmol Vis Sci. 2009; 50(7):3203-3209.

47. Koh S, Maeda N, Hirohara Y, et al. Serial measurements of higher-order aberrations after blinking in patients with dry eye. Invest Ophthalmol Vis Sci. 2008;49(1):133-138.

48. Montés-Micó R, Alió JL, Charman WN. Postblink changes in the ocular modulation transfer function measured by a double-pass method. Invest Ophthalmol Vis Sci. 2005;46(12):4468-4473.

49. Puell MC, Benítez-del-Castillo JM, Martínez-de-la-Casa J, et al. Contrast sensitivity and disability glare in patients with dry eye. Acta Ophthalmol Scand. 2006;84(4):527-531.

50. Rolando M, Iester M, Macri A, Calabria G. Low spatial-contrast sensitivity in dry eyes. Cornea. 1998;17(4):376-379.

51. Tutt R, Bradley A, Begley C, Thibos LN. Optical and visual impact of tear break-up in human eyes. Invest Ophthalmol Vis Sci. 2000;41(13):4117-4123.

52. Pflugfelder SC, Tseng SC, Sanabria O, et al. Evaluation of subjective assessments and objective diagnostic tests for diagnosing tear-film disorders known to cause ocular irritation. Cornea. 1998;17(1):38-56.

53. Cohen KL. Sterile comeal perforation after cataract surgery in Sjogren's syndrome. Br J Ophthalmol. 1982;66(3):179-182.

54. Li XM, Hu L, Hu J, Wang W. Investigation of dry eye disease and analysis of the pathogenic factors in patients after cataract surgery Cornea. 2007;26(9 Suppl 1):S16-S20.

55. Ring L, Okoro M. Handbook of Ophthalmic Nursing Standards \& Procedures. Keswick, UK: M \& K Update Ltd; 2012. 
56. American Academy of Ophthalmology Cataract and Anterior Segment Panel. The Cataract in the Adult Eye Preferred Practice Pattern. San Francisco, CA: American Academy of Ophthalmology; 2016.

57. Abelson MB, Ousler GW 3rd, Nally LA, Welch D, Krenzer K. Alternative reference values for tear film break up time in normal and dry eye populations. Adv Exp Med Biol. 2002;506(Pt B):1121-1125.

58. Wong J, Lan W, Ong LM, Tong L. Non-hormonal systemic medications and dry eye. Ocul Surf. 2011;9(4):212-226.

59. Mah FS, O'Brien T, Kim T, Torkildsen G. Evaluation of the effects of olopatadine ophthalmic solution, $0.2 \%$ on the ocular surface of patients with allergic conjunctivitis and dry eye. Curr Med Res Opin. 2008;24(2):441-447.

60. Ousler GW 3rd, Workman DA, Torkildsen GL. An open-label, investigator-masked, crossover study of the ocular drying effects of two antihistamines, topical epinastine and systemic loratadine, in adult volunteers with seasonal allergic conjunctivitis. Clin Ther. 2007; 29(4):611-616.
61. Sekeroglu MA, Hekimoglu E, Tasci Y, Dolen I, Arslan U. Ocular surface changes following oral anticholinergic use for overactive bladder. Cutan Ocul Toxicol. 2016;35(3):218-221.

62. Ozen Tunay Z, Ozdemir O, Ergintürk Acar D, Cavkaytar S, Ersoy E. Dry eye findings worsen with anticholinergic therapy in patients with urge incontinence. Int Urogynecol J. 2016;27(6):919-922.

63. Acan D, Kurtgoz P. Influence of selective serotonin reuptake inhibitors on ocular surface. Clin Exp Optom. 2017;100(1):83-86. 


\section{Supplementary material}

Table SI Dry eye signs and symptoms

\begin{tabular}{lll}
\hline Parameter evaluated & $\mathbf{n}$ & $\%$ \\
\hline $\begin{array}{l}\text { Stinging and burning } \\
\text { Frequency }\end{array}$ & & \\
None of the time & 94 & 69.1 \\
Some of the time & 32 & 23.5 \\
Half of the time & 4 & 2.9 \\
Most of the time & 4 & 2.9 \\
All of the time & 2 & 1.5
\end{tabular}

How bothered by each symptom? ( $0=$ not at all; $4=$ extremely)

$\begin{array}{lll}0 & 90 & 69.2 \\ 1 & 19 & 14.6 \\ 2 & 13 & 10.0 \\ 3 & 5 & 3.8 \\ 4 & 3 & 2.3\end{array}$

\section{Dryness}

Frequency

None of the time 86

Some of the time 29

Half of the time II

Most of the time 6

All of the time

How bothered by each symptom? ( $0=$ not at all; $4=$ extremely)

$\begin{array}{ll}0 & 82 \\ 1 & 23 \\ 2 & 13 \\ 3 & 6 \\ 4 & 4\end{array}$

Foreign body sensation

Frequency

None of the time $\quad 80 \quad 59.3$

Some of the time $38 \quad 28.1$

Half of the time $\quad 4 \quad 3.0$

$\begin{array}{lll}\text { Most of the time } & 10 & 7.4\end{array}$

All of the time

3

How bothered by each symptom? $(0=$ not at all; $4=$ extremely $)$

$\begin{array}{lll}0 & 75 & 58 \\ 1 & 34 & 26.4 \\ 2 & 8 & 6.2 \\ 3 & 8 & 6.2 \\ 4 & 4 & 3.1\end{array}$

Itching

Frequency

None of the time 73

Some of the time $\quad 47 \quad 34.8$

Half of the time 12

Most of the time ।

All of the time

2

How bothered by each symptom? ( $0=$ not at all; $4=$ extremely)

\begin{tabular}{lll}
0 & 72 & 55.0 \\
1 & 33 & 25.2 \\
2 & 19 & 14.5 \\
3 & 2 & 1.5 \\
4 & 5 & 3.8 \\
\hline
\end{tabular}

(Continued)
Table SI (Continued)

\begin{tabular}{lll}
\hline Parameter evaluated & $\mathbf{n}$ & $\%$ \\
\hline $\begin{array}{l}\text { Sensitivity to light } \\
\text { Frequency }\end{array}$ & & \\
None of the time & 53 & 39.6 \\
Some of the time & 40 & 29.9 \\
Half of the time & 11 & 8.2 \\
Most of the time & 13 & 9.7 \\
All of the time & 17 & 12.7
\end{tabular}

How bothered by each symptom? ( $0=$ not at all; $4=$ extremely)

$\begin{array}{lll}0 & 50 & 38.5\end{array}$

$\begin{array}{lll}1 & 35 & 26.9\end{array}$

$\begin{array}{lll}2 & 26 & 20.0\end{array}$

$\begin{array}{lll}3 & 8 & 6.2\end{array}$

$\begin{array}{lll}4 & \text { II } & 8.5\end{array}$

Painful/sore

Frequency

$\begin{array}{lll}\text { None of the time } & 107 & 78.7\end{array}$

Some of the time $\quad 21 \quad 15.4$

Half of the time $\quad 5 \quad 3.7$

$\begin{array}{lll}\text { Most of the time } & \text { I } & 0.7\end{array}$

All of the time $2 \quad 1.5$

How bothered by each symptom? ( $0=$ not at all; $4=$ extremely)

$\begin{array}{lll}0 & 103 & 79.2\end{array}$

$\begin{array}{lll}1 & 11 & 8.5\end{array}$

$\begin{array}{lll}1 & 10 & 7.7\end{array}$

$\begin{array}{lll}3 & 3 & 2.3\end{array}$

423.3

Blurred vision

Frequency

None of the time $46 \quad 34.1$

Some of the time $\quad 50 \quad 37.0$

Half of the time II 8.1

$\begin{array}{lll}\text { Most of the time } & 14 & 10.4\end{array}$

$\begin{array}{lll}\text { All of the time } & 14 & 10.4\end{array}$

How bothered by each symptom? ( $0=$ not at all; $4=$ extremely)

$\begin{array}{lll}0 & 44 & 33.6\end{array}$

$\begin{array}{lll}\text { I } & 28 & 21.4\end{array}$

$\begin{array}{lll}2 & 30 & 22.9\end{array}$

$\begin{array}{lll}3 & 14 & 10.7\end{array}$

$\begin{array}{lll}4 & 15 & 11.5\end{array}$

Tired/fatigued eyes

Frequency

None of the time $\quad 65 \quad 47.8$

Some of the time $51 \quad 37.5$

Half of the time $\quad 96.6$

Most of the time $\quad 7 \quad 5.1$

All of the time 4.9

How bothered by each symptom? ( $0=$ not at all; $4=$ extremely)

$\begin{array}{lll}0 & 67 & 50.8 \\ 1 & 31 & 23.5 \\ 2 & 21 & 15.9 \\ 3 & 8 & 6.1 \\ 4 & 5 & 3.8\end{array}$

Note: Not all eligible patients $(\mathrm{N}=136)$ answered every question. 


\section{Publish your work in this journal}

Clinical Ophthalmology is an international, peer-reviewed journal covering all subspecialties within ophthalmology. Key topics include: Optometry; Visual science; Pharmacology and drug therapy in eye diseases; Basic Sciences; Primary and Secondary eye care; Patient Safety and Quality of Care Improvements. This journal is indexed on

Submit your manuscript here: http://www.dovepress.com/clinical-ophthalmology-journal
PubMed Central and CAS, and is the official journal of The Society of Clinical Ophthalmology (SCO). The manuscript management system is completely online and includes a very quick and fair peer-review system, which is all easy to use. Visit http://www.dovepress.com/ testimonials.php to read real quotes from published authors. 